DE

M E D I C I N A

T R O P I C A L

$\mathrm{DE}$

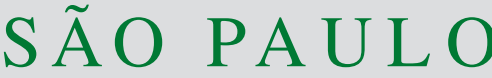

JOURNAL OF THE SÃO PAULO INSTITUTE OF TROPICAL MEDICINE

(1)Fundação Oswaldo Cruz, Instituto Aggeu Magalhães, Recife, Pernambuco, Brazil

(2) Universidade de Pernambuco, Instituto de Ciências Biológicas, Recife, Pernambuco, Brazil

Correspondence to: Zulma Maria de Medeiros

Fundação Oswaldo Cruz, Instituto Aggeu Magalhães, Av. Prof. Moraes Rego, s/n, CEP 50740-465, Recife, PE, Brazil.

E-mail: medeiros@cpqam.fiocruz.br

Received: 22 November 2016

Accepted: 22 February 2017

\section{Characterization of Leishmania (L.) infantum chagasi in visceral leishmaniasis associated with hiv co-infection in Northeastern Brazil}

\author{
Elaine Cristina Bomfim de Lima ${ }^{1}$, Walter Lins Barbosa Júnior ${ }^{1}$, Maria \\ Edileuza Felinto de Brito', Fábio Lopes de Melo', Sinval Pinto Brandão \\ Filho' $^{1}$, Zulma Maria de Medeiros ${ }^{1,2}$
}

\section{ABSTRACT}

Visceral leishmaniasis, associated with HIV/AIDS coinfection, is becoming a more aggressive disease, complicating an accurate prognosis. A 21-year-old HIV-positive female presenting with clinical features of visceral leishmaniasis was enrolled in this study. Bone marrow cytology, Novy-MacNeal-Nicolle culture and kDNA PCR of peripheral blood were all positive. Typing methods, multilocus enzyme electrophoresis and ITS1-RFLP PCR of peripheral blood confirmed infection by Leishmania (L.) infantum chagasi. PCR has proved to be safer and more affordable than other characterization methods; ITS1-RFLP PCR can diagnose and type Leishmania spp. in both endemic and non-endemic areas, favoring the prognosis and allowing the appropriate treatment of patients.

KEYWORDS: Characterization. Leishmania (L.) infantum chagasi. Visceral leishmaniasis. HIV/AIDS. Coinfection.

Visceral leishmaniasis (VL) caused by Leishmania (L.) infantum chagasi is a severe disease that takes the lives of thousands of people every year. Since the 1980s, the human immunodeficiency virus (HIV)/acquired immunodeficiency syndrome (AIDS) has increased the number of VL-HIV/AIDS coinfection cases reported in Europe, Africa, Asia and Latin America ${ }^{1,2}$.

Clinical diagnosis of VL-HIV/AIDS coinfection is difficult, as Leishmania species may initially cause non-specific clinical features in some patients, even when associated with epidemiological data ${ }^{3}$.

Cytological examination of spleen, bone marrow and/or lymph node stainedsmears are considered the gold standards for VL-HIV/AIDS diagnosis. Nonetheless, cytology may increase the risk of adverse events in patients, as invasive procedures are required to obtain these samples ${ }^{4}$. The culture in NNN (Novy-MacNealNicolle) medium to isolate parasites is the classical procedure recommended for the identification of Leishmania spp., and is essential for characterization based on multilocus enzyme electrophoresis (MLEE) $)^{5,6}$, the gold standard method for Leishmania spp. identification ${ }^{7}$. Nonetheless, this may require samples obtained by invasive procedures (e.g., spleen, bone marrow or lymph node). Moreover, culture may be time-consuming and difficult to perform at primary health care facilities ${ }^{3}$.

Disease control requires efficient monitoring, rapid identification of Leishmania strains and management of molecular tools ${ }^{8}$. Polymerase chain reaction (PCR) is a powerful tool for detecting Leishmania DNA in bone marrow aspirates, blood samples and lymph nodes and has shown to be more sensitive than parasitological 
methods. Nowadays, there are too many targets for visceral leishmaniasis detection and the choice of primers is important because each target has its own sensitivity and specificity ${ }^{9,10}$. Le Fichoux et al. ${ }^{11}$ have used RV1 and RV2 primers to amplify kinetoplast minicircle sequences (kDNA), which are the most commonly used target for VL diagnosis. Schönian et al. ${ }^{12}$ have used LITSR and L5.8S primers to identify Leishmania species and the lineage of strains by ITS1-RFLP PCR.

The present study describes the clinical, epidemiological and molecular characterization of Leishmania ( $L$. ) infantum chagasi isolated from a visceral leishmaniasis/HIV coinfected patient, outlining the usefulness of the methods adopted here and showing which is the most affordable.

A 21-year-old HIV-positive female lived in the Agreste region of Northeastern Brazil, an area endemic of visceral leishmaniasis. She had presented with clinical features of visceral leishmaniasis and been referred to Hospital Universitário Oswaldo Cruz, Recife, in the State of Pernambuco. Anemia associated with anisocytosis and microcytosis, leukopenia with lymphopenia and neutropenia were the most frequent laboratory alterations found. She had presented with episodes of fever, splenomegaly, pale mucous membranes and weight loss of over $5 \mathrm{~kg}$ in four months. All these data were available in the patient's clinical records. Bone marrow and peripheral blood samples were collected.

The aim of the study was to carry out a pioneering evaluation that applied a set of characterization methods for the detection of Leishmania spp. in an HIV-positive patient. Bone marrow cytology was carried out to search for amastigote forms by optical microscopy. In parallel, $200 \mu \mathrm{L}$ of bone marrow were inoculated under sterile conditions in NNN culture tubes; $500 \mu \mathrm{L}$ of NNN/Schneider two-phase medium were added to increase and accelerate the positivity of cultures. Promastigote forms were visualized by optical microscopy using $10 \mu \mathrm{L}$ of culture ${ }^{13}$. The isolate was submitted to multilocus enzyme electrophoresis (MLEE).

MLEE was performed with the following enzyme extracts: glucose-phosphate isomerase (GPI, E.C.5.3.1.9), glucose6-phosphate dehydrogenase (G6PDH, E.C.1.1.1.49), isocitrate dehydrogenase with NAD and NADP (IDHNAD IDHNADP, E.C.1.1.1.42) and 6-phosphogluconate dehydrogenase (6PGDH, E.C.1.1.1.43) ${ }^{7}$. This isolate was compared to reference strains of different Leishmania species at the Oswaldo Cruz Institute - FIOCRUZ (CLIOC/ IOC-FIOCRUZ), e.g. Leishmania (L.) infantum chagasi, L. braziliensis, L. guyanensis, L. shawi and L. naiff to determine the species.

Peripheral blood DNA extraction was carried out using the commercial extraction kit-illustra ${ }^{\mathrm{TM}}$ tissue
\& cells genomic Prep Mini Spin Kit (GE Healthcare, Buckinghamshire, UK), for the PCR methods. NanoDrop 2000 (Thermo Scientific Nano Drop Products) was used to determine the DNA concentration.

In kDNA PCR, the reaction mixture $(25 \mu \mathrm{L}$ of total volume) was prepared containing a buffer of $1 \mathrm{X}$ Invitrogen, $0.25 \mathrm{mM}$ dNTPs, $1.5 \mathrm{mM} \mathrm{MgCl}_{2}, 2.5$ units of Taq polymerase (Platinum ${ }^{\circledR}$, Invitrogen, Carlsbad, $\mathrm{CA}$ ), $2 \mu \mathrm{L}$ of DNA (14 ng/ $\mu \mathrm{L}$ ), $25 \mathrm{pmol}$ of each primer, RV1 (5'- CTTTTCTGGTCCCGCGGGTAGG) and RV2 (5' - CACCTGGCCTATTTTACACCA $)^{11}$, amplifying a conserved region of the minicircle kDNA of Leishmania. After an initial denaturation $\left(5 \mathrm{~min}\right.$ at $\left.94{ }^{\circ} \mathrm{C}\right), 35$ cycles (denaturation, $30 \mathrm{sec}$ at $94{ }^{\circ} \mathrm{C}$; annealing, $1 \mathrm{~min}$ at $67^{\circ} \mathrm{C}$; extension $30 \mathrm{sec}$ at $72{ }^{\circ} \mathrm{C}$ ) were performed and PCR was concluded by a final extension at $70^{\circ} \mathrm{C}$ for $10 \mathrm{~min}$. This PCR assay achieved a maximum analytical sensitivity of $100 \mathrm{fg}$. DNA amplification was performed in a LifePro thermal cycler (Hangzhou Bioer Technology, Binjiang, China). All reactions included a positive and a negative control. The expected final product was $145 \mathrm{bp}$. The amplification products were visualized by horizontal electrophoresis in $2 \%$ ethidium bromide-stained agarose gels.

The ITS1 PCR reaction mixture ( $50 \mu \mathrm{L}$ of total volume) was prepared containing $25 \mu \mathrm{L} 2 \times$ GoTaq $^{\circledR}$ Green Master Mix (Promega Corp., Madison, WI), 50 pmol of primers: LITSR (5'CTGGATCATTTTCCGATG) and L5.8S $\left(5^{\prime} \text { TGATACCACTTATCGCACTT }\right)^{12}$, amplifying a portion of the internal transcribed spacer 1 (ITS1) non-coding region found in the SSU rRNA delimited by the $5.8 \mathrm{~S}$ and $18 \mathrm{~S}$ genes. After an initial denaturation $\left(3 \mathrm{~min}\right.$ at $\left.95{ }^{\circ} \mathrm{C}\right), 35$ cycles (denaturation, $40 \mathrm{sec}$ at $95{ }^{\circ} \mathrm{C}$; annealing, $45 \mathrm{sec}$ at $53^{\circ} \mathrm{C}$; extension 1 min at $72{ }^{\circ} \mathrm{C}$ ) were carried out and PCR was concluded by a final extension at $70{ }^{\circ} \mathrm{C}$ for $6 \mathrm{~min}$. This PCR assay achieved a maximum analytical sensitivity of $100 \mathrm{fg}$. Reactions were performed with $2 \mu \mathrm{L}(14 \mathrm{ng} / \mu \mathrm{L}), 5 \mu \mathrm{L}$ and $10 \mu \mathrm{L}$ of DNA and included a positive and a negative control. The expected amplification product was 300-350 bp and they were visualized by horizontal electrophoresis in $2 \%$ ethidium bromide-stained agarose gels.

Restriction enzyme analyses (RFLP) were performed in a total volume of $15 \mu \mathrm{L}$ containing the ITS1 PCR product digested by the restriction enzyme HaeIII without prior purification, under the conditions recommended by the supplier (Hybaid GmbH Heidelberg, GE). ITS1- RFLP PCR was also tested on Leishmania strains from both, an endemic and a non-endemic area in Northeastern Brazil. The product underwent electrophoresis on $4.0 \%$ ethidium bromide-stained agarose gels. The band patterns from the prototypes were compared to the RFLP patterns of the clinical sample. 
The increasing number of visceral leishmaniasis/HIV coinfection cases in Brazil is worrying, in view of the inherent risk of developing VL when HIV is present ${ }^{14-16}$. Additionally, the cumulative immunosuppression accelerates the clinical progression of both infections ${ }^{17}$. In the present study, the female patient presented classical clinical and epidemiological features of VL infection.

In endemic regions, where multiple species of Leishmania may coexist, geographical distribution may be an inadequate criterion. Clinical symptoms can be problematic for identification of the infecting species, since some cause both cutaneous and mucocutaneous disease $(L$. braziliensis complex, L. aethiopica), while others cause both visceral and cutaneous disease (e.g. L. donovani complex) $)^{12}$.

Bone marrow cytology has variable sensitivities in both immunocompetent and immunosuppressed patients ${ }^{4,18}$. However, higher sensitivities of bone marrow cytology found in HIV-patients have been attributed to more intense Leishmania parasitemias in this group. Furthermore, the low number of Leishmania-infected cells in patients with pancytopenia, as well as those who have received previous treatments, may lead to false-negative results ${ }^{3}$. Bone marrow cytology should be requested when low sensitivity serological tests were performed alone, in order to avoid false-negative results. The patient in the present study had a positive bone marrow cytology.

It is recommended to perform culture isolation of Leishmania in parallel with bone marrow-stained smears in HIV-positive patients with symptoms (e.g. fever, visceromegaly, or hematological abnormalities), as VL/HIV coinfection diagnosis is difficult ${ }^{3}$. The patient had a Leihmania spp. positive culture.

The allelic variation of this strain was tested using a panel of five enzymes by MLEE, confirming the presence of Leishmania (L.) infantum chagasi IOC-L 3328 (MHOM/ BR/2011/COS). One PCR target was the kinetoplast minicircle, which led to detection of Leishmania DNA in this clinical sample (data not shown). Amplification of this region is frequently chosen as the target for human kala-azar molecular diagnosis because of its higher sensitivity due to multi-copy number sequences ${ }^{9,10}$. PCR has consistently shown to be better than direct examination and culture, particularly in samples with low parasitic load ${ }^{19}$. Kinetoplast DNA PCR has been successfully used to identify Leishmania in blood samples of symptomatic and asymptomatic, immunocompetent and immunocompromised patients. Nevertheless, the kinetoplast is a heterogeneous target for which a great diversity of primers has been described and this may result in loss of assay accuracy, complicating the construction of RFLP patterns. However, it does distinguish a few selected species, such as $L$. infantum, $L$. donovani and L. major ${ }^{9,10,18}$.

The last PCR assay, targeting the ITS1 region, detected Leishmania DNA in a blood sample. PCR targeting the non-coding region found in the SSU rRNA has provided good results and proved to be substantially more sensitive than microscopic examination, especially in cases of HIV-coinfection ${ }^{10}$. The main advantage of ITS1 PCR over kDNA PCR is that the former can distinguish many clinically important Leishmania species through RFLP patterns $^{9,12}$. ITS1-RFLP PCR in Leishmania trains from endemic and non-endemic areas in Northeastern Brazil was able to establish specific patterns (Figure 1). In this clinical sample, $2 \mu \mathrm{L}(14 \mathrm{ng} / \mu \mathrm{L})$ and $5 \mu \mathrm{L}$ of DNA were insufficient to establish RFLP patterns after ITS1 PCR, but $10 \mu \mathrm{L}$ did work (Figures 2A, 2B), thus confirming Leishmania (L.) infantum chagasi species.

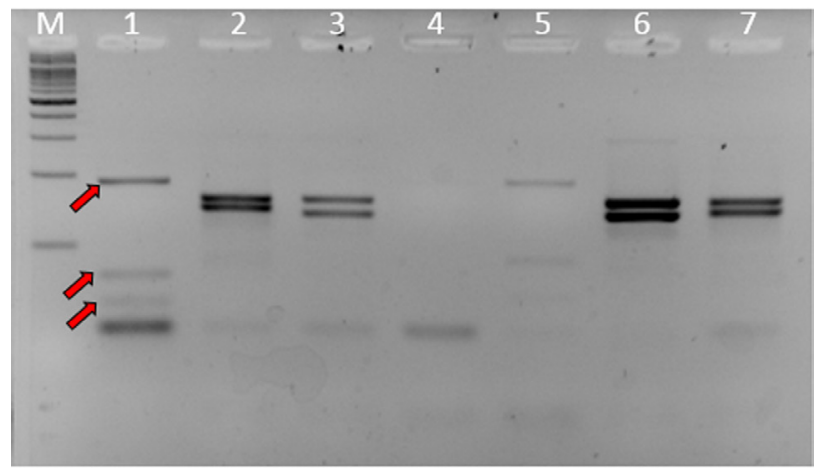

Figure 1 - ITS1-RFLP PCR of different Leishmania species with the restriction endonuclease Hae III. M - 100 bp marker (Promega $\left.{ }^{\circledR}\right) ; 1$ - Leishmania (L.) infantum chagasi; 2 - L. braziliensis; 3 - L. amazonensis; 4 - L. guyanensis; 5 - L. mexicana; 6 - L. lainsoni; 7 - L. shawi. Specific fragments of Leishmania (L.) infantum chagasi are indicated by the arrow

Characterization of Leishmania spp. makes it possible to conduct epidemiological studies and assess the Leishmania population, besides targeting more accurate disease control measures. PCR-based methods that use blood samples have proved to be safer and more affordable than the other characterization methods mentioned above; especially ITS1-RFLP PCR, which can determine the levels of Leishmania spp. in both endemic and non-endemic areas favoring the prognosis and allowing the appropriate treatment of patients.

\section{ACKNOWLEDGMENTS}

This study was supported by CAPES, CNPq and FACEPE grants. We would like to thank the staff of Hospital Universitário Oswaldo Cruz and the Leishmania collection of the Oswaldo Cruz Institute for their collaboration. 

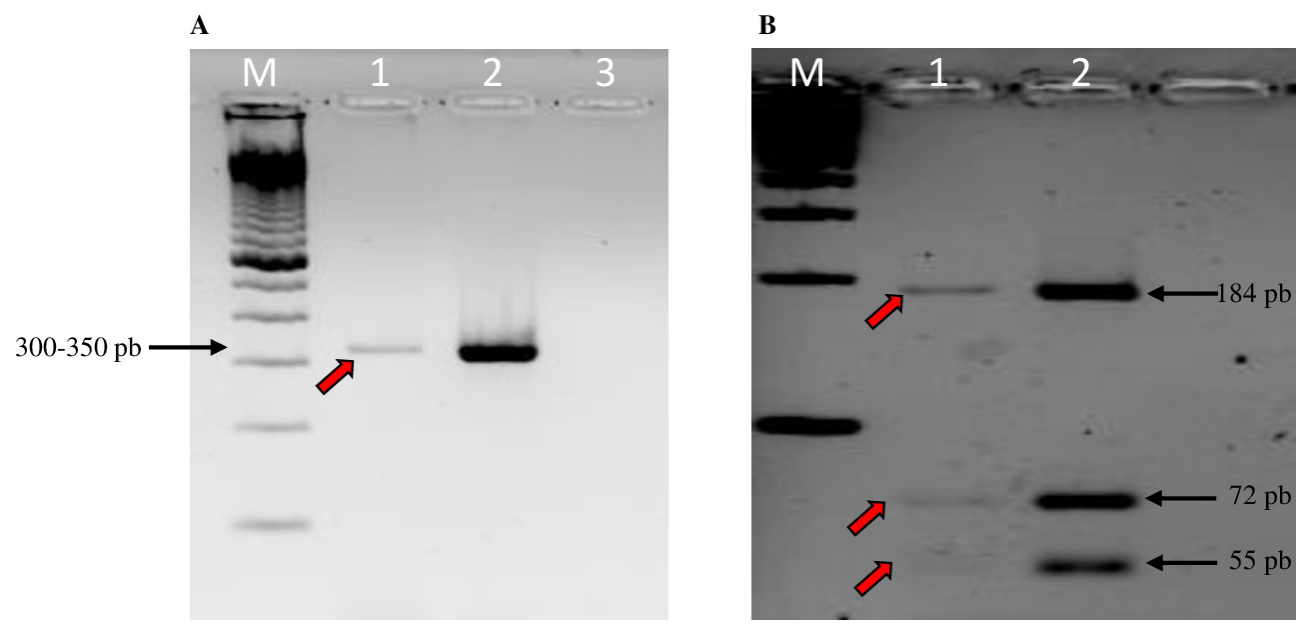

Figure 2 - ITS1 PCR product (A) and RFLP PCR with Hae III (B) for typing of Leishmania spp. The positive control and the clinical sample had amplification products of 300-350 bp (MHOM/BR/1974/PP75). The clinical sample (MHOM/BR/2011/COS), indicated by the arrow, showed a banding pattern matching the one of Leishmania (L.) infantum chagasi. M -100 bp marker (Promega®); 1- Clinical strain; 2- Positive control; 3-Negative control

\section{REFERENCES}

1. Cruz I, Nieto J, Moreno J, Cañavate C, Desjeux P, Alvar J. Leishmania/HIV co-infections in the second decade. Indian J Med Res. 2006;123:357-88.

2. Alemayehu M, Wubshet M, Mesfin N. Magnitude of visceral leishmaniasis and poor treatment outcome among HIV patients: meta-analysis and systematic review. HIV AIDS (Auckl). 2016;8:75-81.

3. Alvar J, Aparicio P, Aseffa A, Boer MD, Cañavate C, Dedet JP, et al. The relationship between leishmaniasis and AIDS: the second 10 years. Clin Microbiol Rev. 2008;21:334-59.

4. Zijlstra EE, Ali MS, el-Hassan AM, el-Toum IA, Satti M, Ghalib HW, et al. Kala-azar: a comparative study of parasitological methods and the direct agglutination test in diagnosis. Trans R Soc Trop Med Hyg. 1992;86:505-7.

5. López-Vélez R, Perez-Molina JA, Guerrero A, Baquero F, Villarrubia J, Escribano L, et al. Clinicoepidemiologic characteristics, prognostic factors, and survival analysis of patients coinfected with human immunodeficiency virus and Leishmania in an area of Madrid, Spain. Am J Trop Med Hyg. 1998;58:436-43.

6. Deniau M, Cañavate C, Faraut-Gambarelli F, Marty P. The biological diagnosis of leishmaniasis in HIV-infected patients. Ann Trop Med Parasitol. 2003;97 Suppl 1:115-33.

7. Cupolillo E, Grimaldi JRG, Momen H. A general classification of new world Leishmania using numerical zymotaxonomy. Am J Trop Med Hyg. 1994;50:296-311.

8. Haralambous C, Antoniou M, Pratlong F, Dedet JP, Soteriadou K. Development of a molecular assay specific for the Leishmania donovani complex that discriminates L.donovani/Leishmania infantum zymodemes: a useful tool for typing MON-1. Diagn Microbiol Infect Dis. 2008;60:33-42.
9. Silva MA, Medeiros RA, Brandão-Filho S, Melo FL, Medeiros Z. Molecular targets used in PCR for the diagnosis of human visceral leishmaniasis. Rev Eletr Farm. 2010;7:1-15.

10. Sakkas H, Gartzonica C, Levidiotou S. Laboratory diagnosis of human visceral leishmaniasis. J Vector Borne Dis. 2016;53:816.

11. le Fichoux Y, Quaranta JF, Aufeuvre JP, Lelievre A, Marty P, Suffia I, et al. Occurrence of Leishmania infantum parasitemia in asymptomatic blood donors living in an area of endemicity in Southern France. J Clin Microbiol. 1999;37:1953-7.

12. Schönian G, Nasereddin A, Dinse N, Schweynoch C, Schallig HD, Presber W, et al. PCR diagnosis and characterization of Leishmania in local and imported clinical samples. Diagn Microbiol Infect Dis. 2003;47:349-58.

13. Brasil. Ministério da Saúde. Secretaria de Vigilância em Saúde. Departamento de Vigilância Epidemiológica. Manual de vigilância e controle da leishmaniose visceral. Brasília: Ministério da Saúde; 2014.

14. Cavalcanti AT, Medeiros Z, Lopes F, Andrade LD, Ferreira VM, Magalhães V, et al. Diagnosing visceral leishmaniasis and HIV/ AIDS co-infection: a case series study in Pernambuco, Brazil. Rev Inst Med Trop Sao Paulo. 2012;54:43-7.

15. Silva ED, Andrade LD, Araújo PS, Silveira VM, Padilha CE, Silva MA, et al. Case study of patient with HIV-AIDS and visceral leishmaniasis co-infection in multiple episodes. Rev Inst Med Trop Sao Paulo. 2013;55:425-8.

16. Barbosa Júnior WL, Araújo PS, Andrade LD, Santos AM, Silva MA, Dantas-Torres FS, et al. Rapid tests and the diagnosis of visceral leishmaniasis and human immunodeficiency virus/ acquired immunodeficiency syndrome coinfection. Am J Trop Med Hyg. 2015;93:967-9.

17. Vassallo M, Moranne O, Ambrosetti D, Jeandel PY, Pomares C, Cassuto E, et al. Visceral leishmaniasis due to Leishmania 
infantum with renal involvement in HIV-infected patients. BMC Infect Dis. 2014;14:561.

18. Cota GF, de Sousa MR, de Freitas Nogueira BM, Gomes LI, Oliveira E, Assis TS, et al. Comparison of parasitological, serological, and molecular tests for visceral leishmaniasis in
HIV-infected patients: a cross-sectional delayed-type study. Am J Trop Med Hyg. 2013;89:570-7.

19. Reithinger R, Dujardin JC. Molecular diagnosis of leishmaniasis: current status and future applications. J Clin Microbiol. 2007:45:21-5 